\title{
Use of Progressive Rock in Donkey Kong Country
}

\section{(1994)}

By: Brooke Spencer

Supervisor: Dr. Stephanie Lind

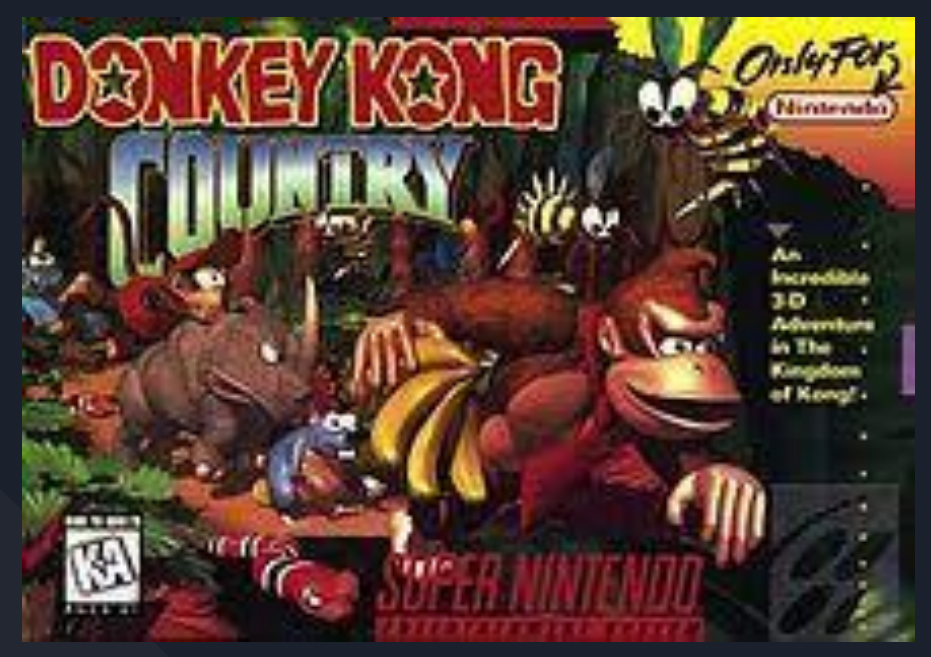


Game Music @ Queens

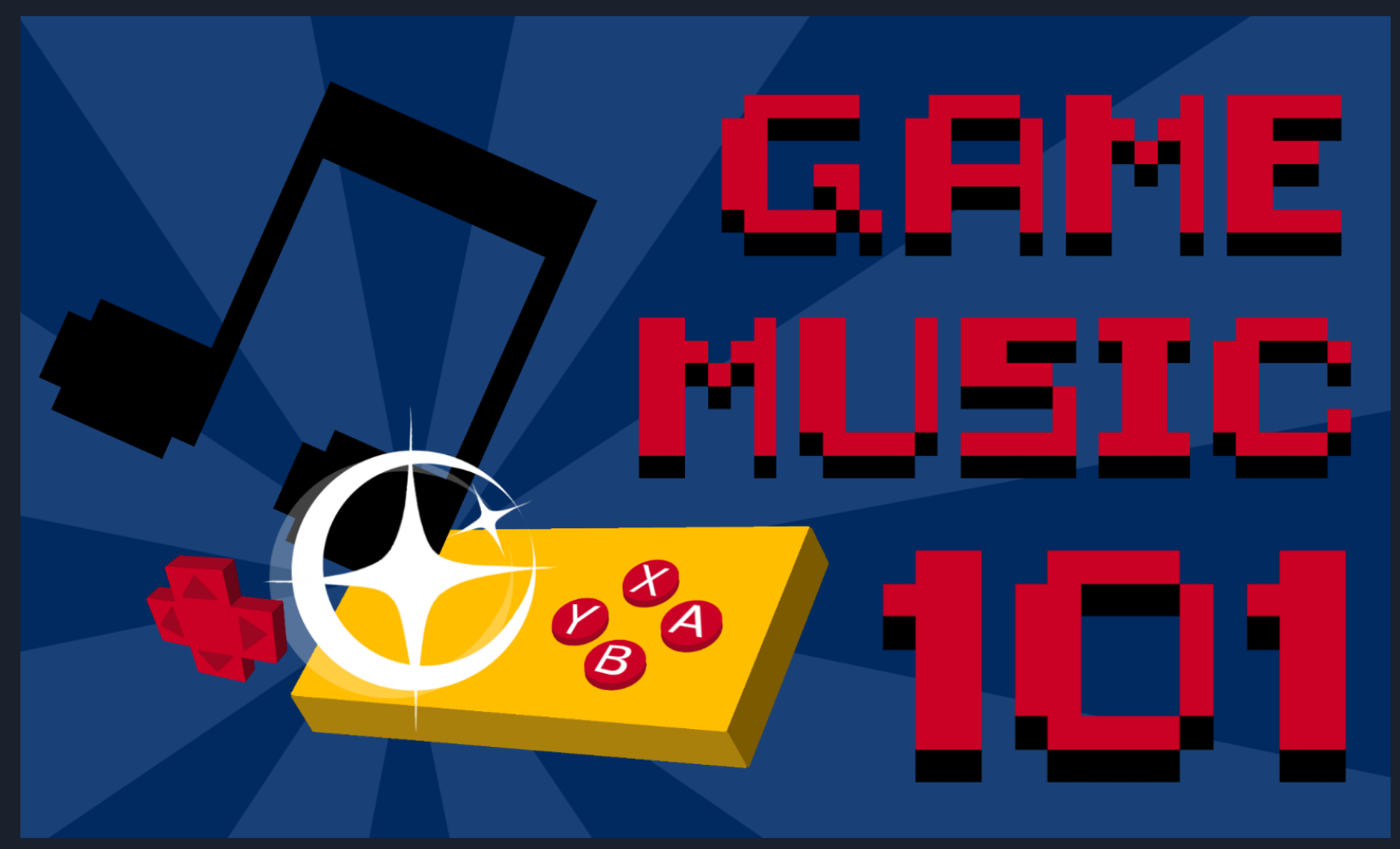




\section{Donkey Kong Country (1994)}

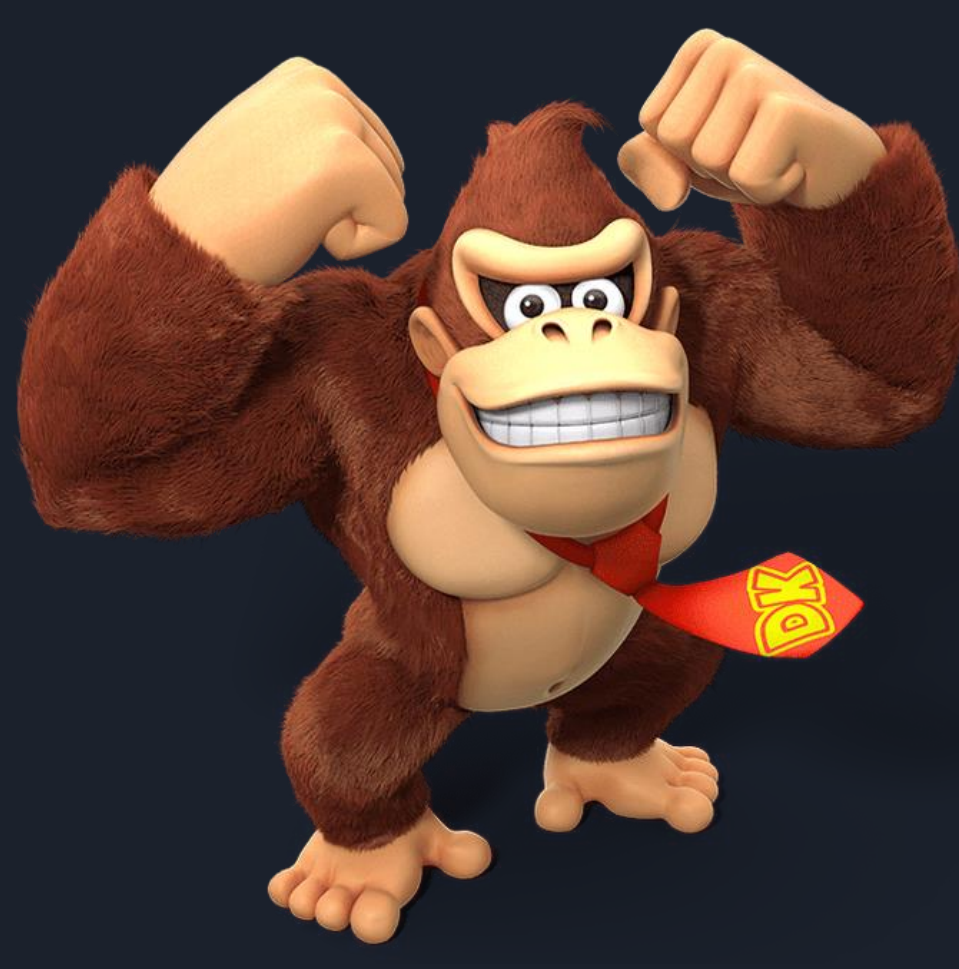

- Expanded range of musical styles, function \& status

- Progressive Rock (prog-rock)

- "Treetop Rock" \& "Fear Factory"

- Use of 'meta-chord' 


\section{History of Videogame Music}

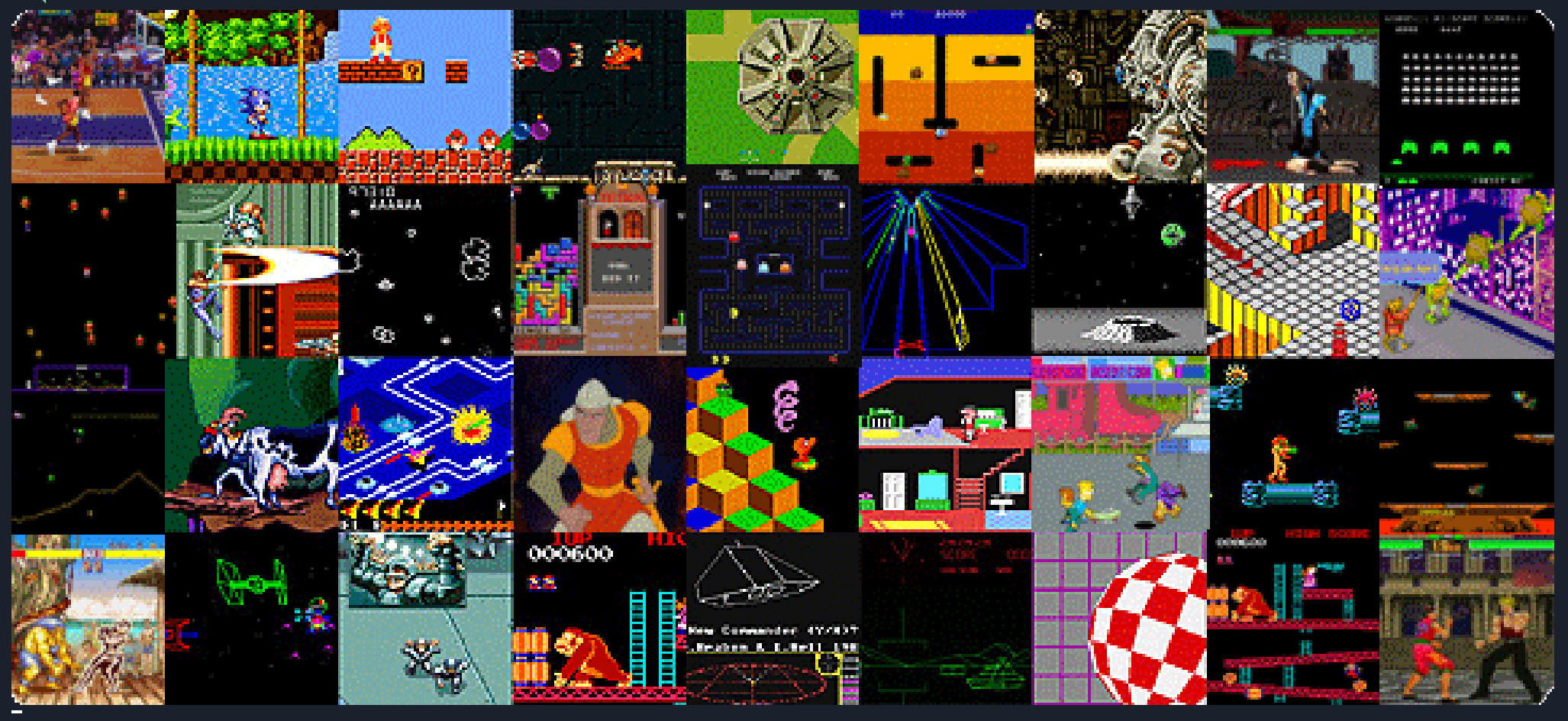




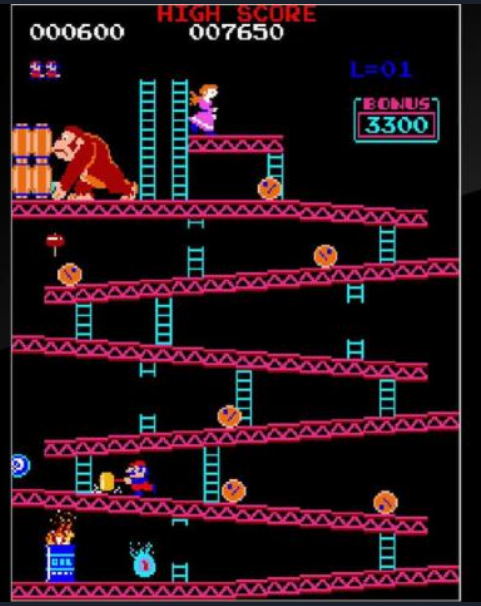




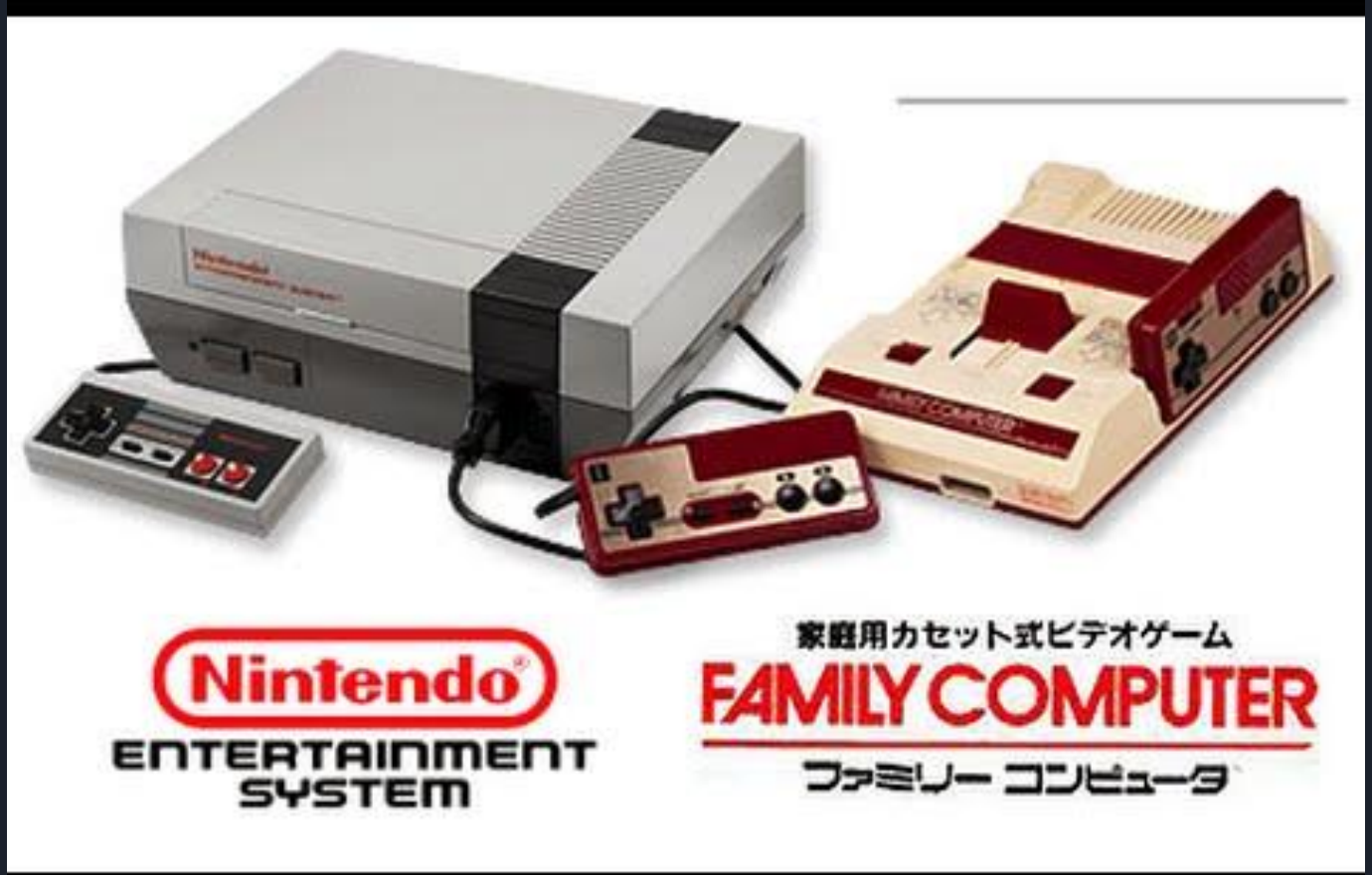



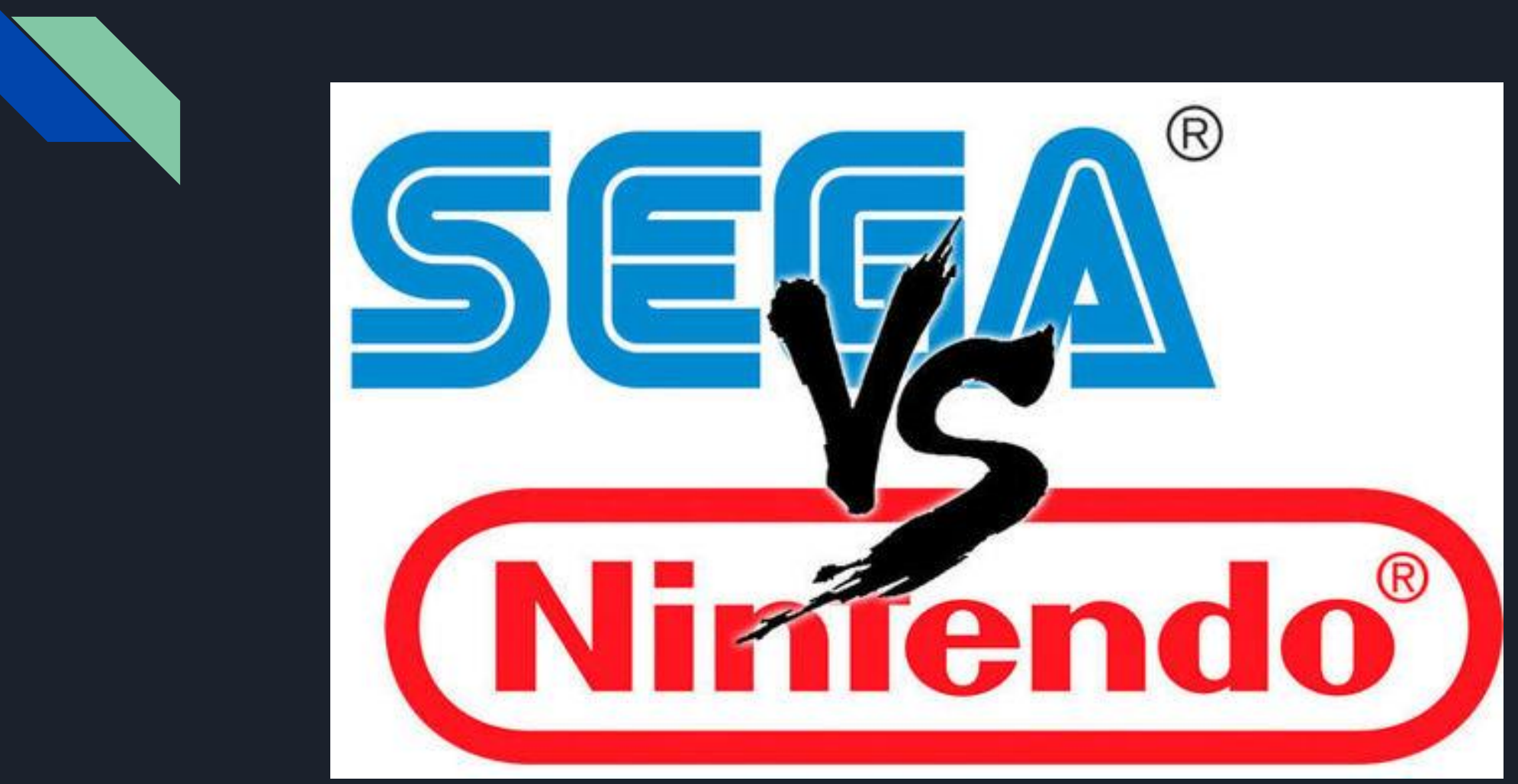

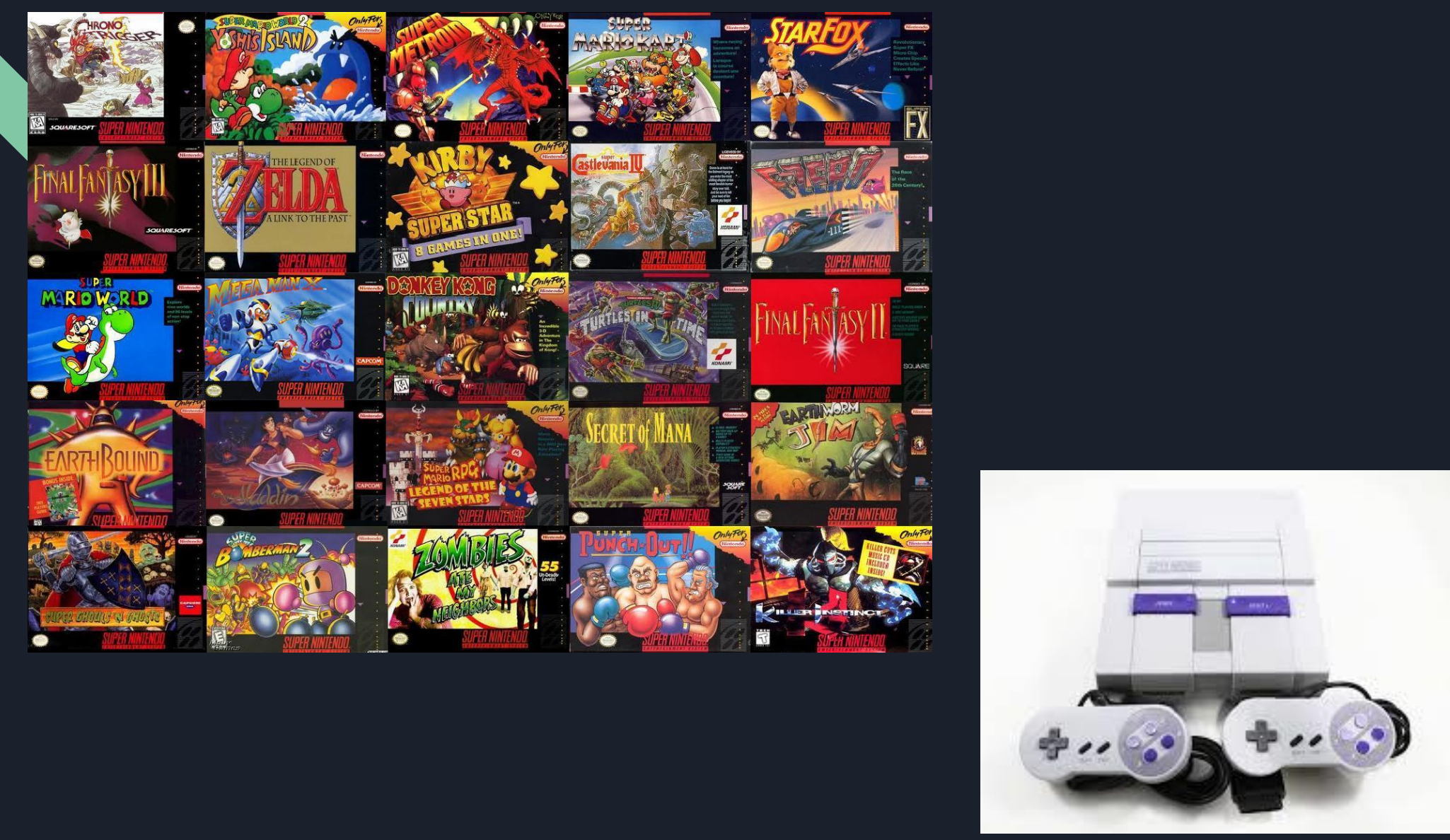




\section{Nintendo's Musical Progress}

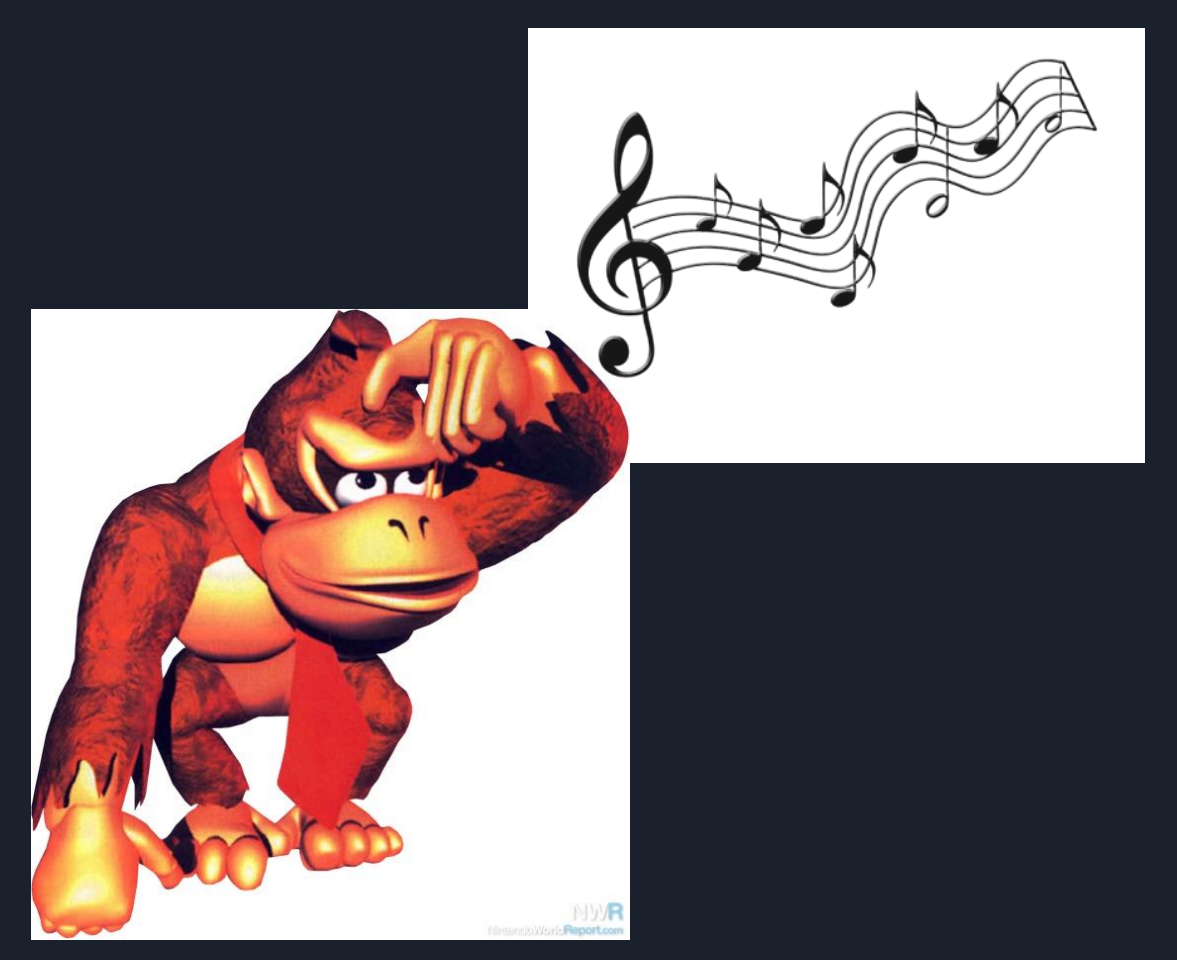

- Re-create standards for their music

- Implement use of prog-rock in their music

- Looking to SEGA's music... 
David Wise
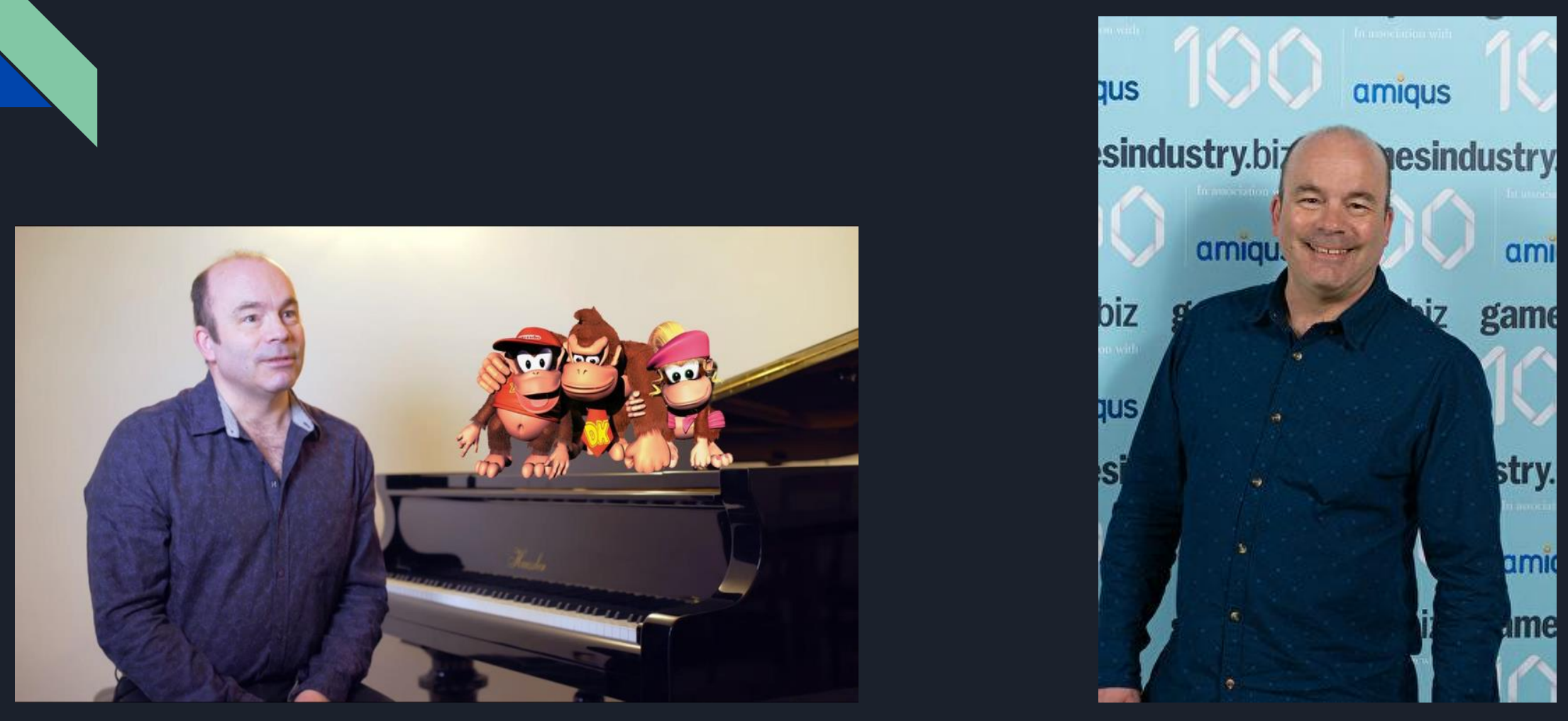


\section{David Wise \& Prog-rock}

- Prog-rock in 1970s

- Common characteristics used: fragmentation, chromaticism, use of modes, distortion, melodic emphasis, \& driving rock rhythms
- Prog-rock in Wise's score for $D K C$

- Used these characteristics $\&$ additionally short repeated melodies, as well as chord progressions with layered harmonies

- "Fear Factory" 


\section{Example: "Fear Factory"}

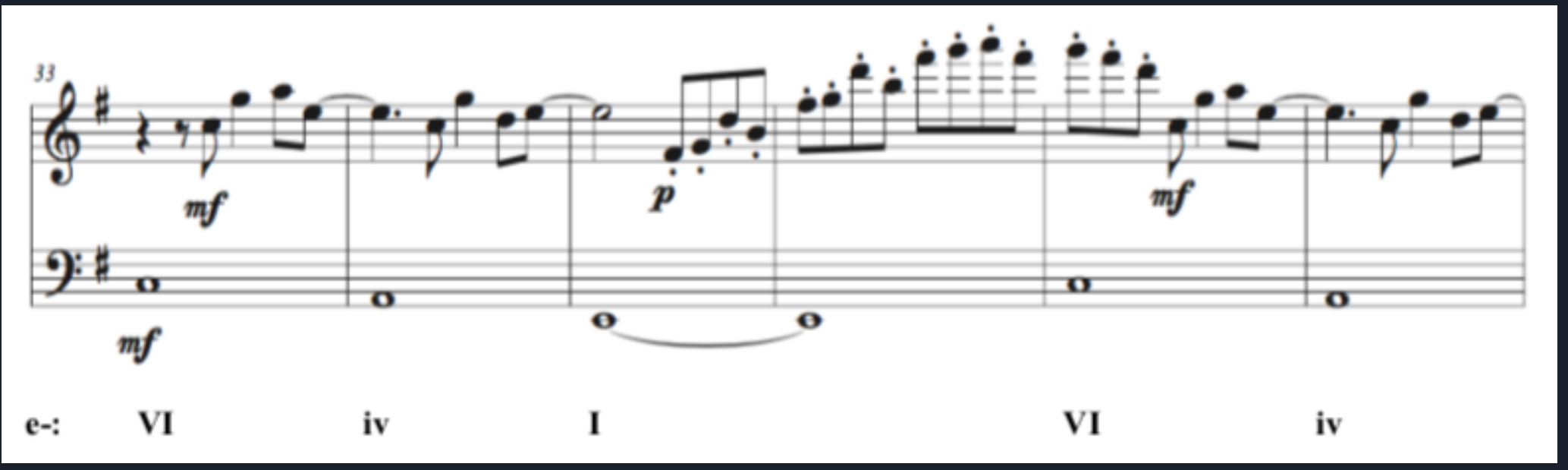

https://www.youtube.com/watch?v=v18pEFQb3EM $0: 57$ 


\section{Linear \& Non-linear Music Used in DKC}

Linearity in "Treetop Rock"= consistent structure \& music looping
Non-linearity in

VS "Treetop Rock"= atmospheric music/personificati on, ambient chords, realistic timbre, synth sound \& 'metachord' 


\section{Section Divisions of "Treetop Rock"}

Intro= ostinato (repeating music pattern), \& syncopated rhythm

$A=$ new voice is added \& prominent marimba melody

$\mathrm{C}=$ more chord movement, modal \& little use of marimba
$B=$ different theme \& new rhythms used
$A / B=$ mix of both elements from $A$ \& B
$A^{\prime}=$ rhyth ms slightly different \& new voice plays marimba melody

Outro= 'final' material \& repeat back to the beginning 


\section{"Treetop Rock"}

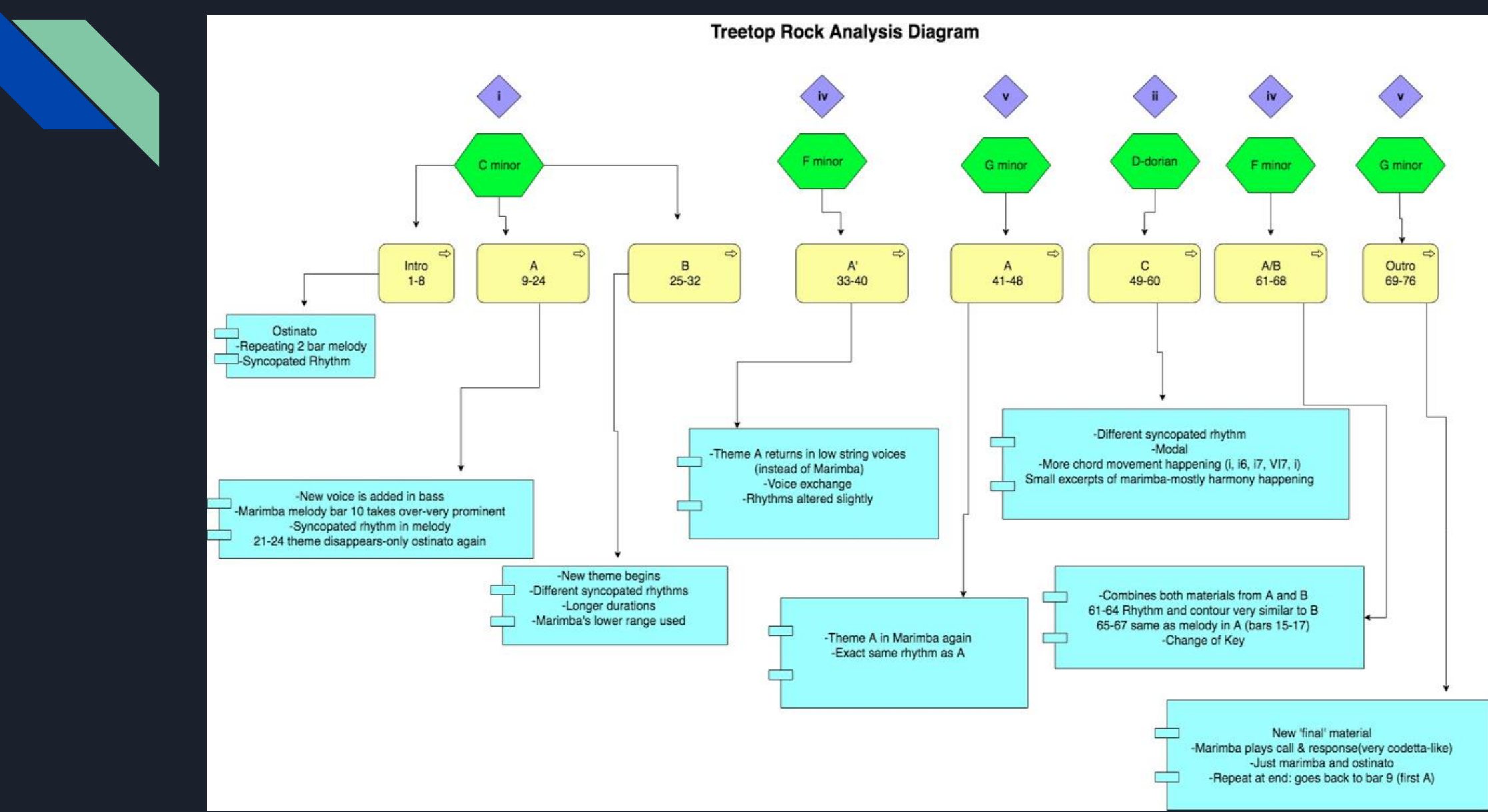



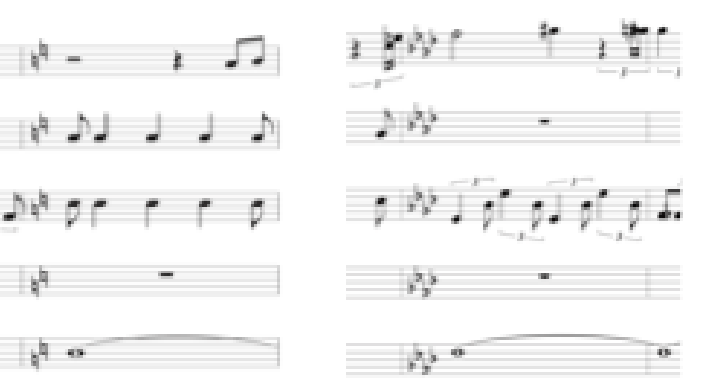

F minor

G minor

D Dorian

F minor

iv

X

ii

iv 


\section{Personification vs. Underscoring in Videogame Music}

- Personification = a connection between a 'mood' or atmosphere and the videogame persona

- Leaves attention for overall feeling

- "The music suggests, rather than reveals"

- Relationship to 'meta-chord'
- Underscoring = no interaction or connection between music and what is happening on screen 


\section{To Summarize}

- Prog-rock

- Use of 'meta-chord'

- Nintendo's advancement in videogame music since

- Influence on later composers

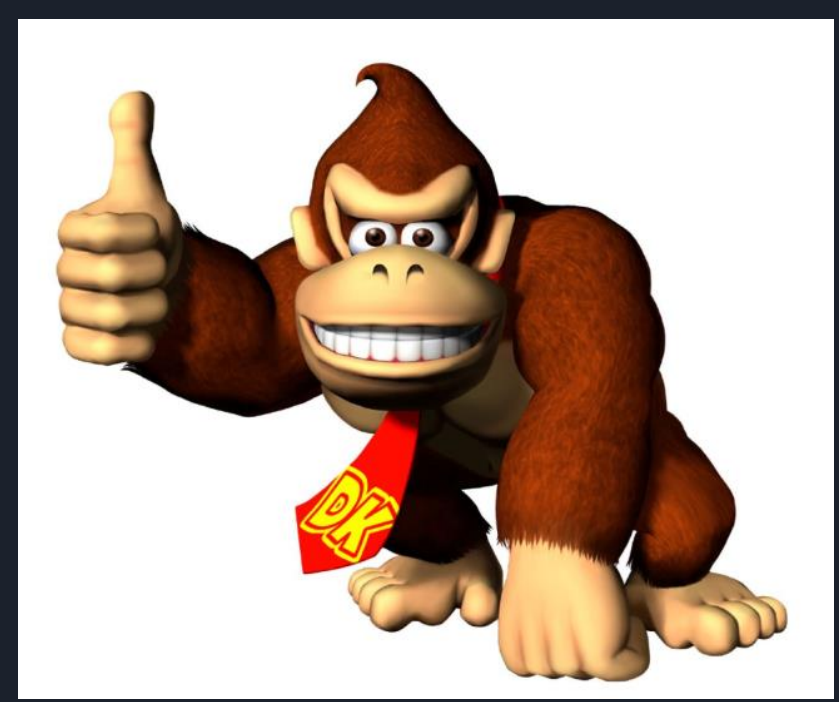




\section{Thank You!}

\section{Works Cited}

8-Bit Music Theory. "4 Tips for Writing Ambient Chord Progressions." February 28th, 2018. www. youtube.com/watch? $v=$ Myc19ZOSPRk\&t=368s.

Böhme, Gernot. Atmosphäre: Essays Zur Neuen Ästhetik. Suhrkamp, 2017.

Cheng, William. Sound Play : Video Games and the Musical Imagination. The Oxford Music/Media Series. 2014.

Collins, Karen. Game Sound: An Introduction to the History, Theory, and Practice of Video Game Music and Sound Design. Cambridge, MA: The MIT Press, 2008.

"Donkey Kong Country Soundtrack- Review." The Greatest Game Music. Accessed September 3rd, 2018, https://www.bestwesterngamesoundtracks.com/soundtracks/donkey-kong-country-soundtrack/

"Progressive Rock and Japanese Video Game Music." The Music of Video Games, 2013, accessed November 13th 2018, adamflip.wordpress.com/2013/12/10/progressive-rock-and-japanese-video-game-music/.

Scotto, Ciro. "The Structural Role of Distortion in Hard Rock and Heavy Metal." Music Theory Spectrum 38, no. 2 (2016): 178-99. https://doi.org/10.1093/mts/mtw013. 